FOLIA

Amazónica

Revista del Instituto de Investigaciones

de la Amazonía Peruana

\title{
APLICACIÓN DEL BARCODING PARA LA ESTIMACIÓN DE LA DIVERSIDAD ESPECÍFICA DE LA FAMILIA LORICARIIDAE (PISCES: SILURIFORMES) EN LA REGIÓN SAN MARTÍN, AMAZONÍA PERUANA
}

\author{
Carlos ANGULO ${ }^{1,2,4}$, Dixner RENGIFO ${ }^{1,2}$ Manuel NAVAS², Erick DEL ÁGUILA², \\ Diana CASTRO-RUIZ ${ }^{1,2,4}$, Homero SÁNCHEZ ${ }^{2,4}$, Aurea GARCÍA-VASQUEZ ${ }^{2,4}$, \\ Eduardo MEJÍA ${ }^{1,2,4}$, Nixon NAKAGAWA ${ }^{2}$, Lisbeth ZUTA², Jean-François RENNO ${ }^{3,4}$, \\ Carmen GARCÍA-DÁVILA ${ }^{1,2,4}$
}
1 Laboratorio de Biología y Genética Molecular (LBGM), Instituto de Investigaciones de la Amazonía Peruana (IIAP), Carretera lquitos-Nauta km 4.5, San Juan Bautista, lquitos, Perú. cdavila19@yahoo.com; cangulo@iiap.org.pe.
2 Programa de Investigación Para el Uso del Agua y sus Recursos (AQUAREC), Instituto de Investigaciones de la Amazonía Peruana (IIAP). Sede Central: Carretera lquitos-Nauta km 4.5, San Juan Bautista, Iquitos, Perú. Sede San Martín: Jr. Belén Torres de Tello 135, Morales, Tarapoto, Perú
3 Institut de Recherche pour le Développement (IRD). Montpellier, France
4 Laboratoire Mixte International - Evolution et Domestication de l'Ichtyofaune Amazonienne (LMI-EDIA)

\section{RESUMEN}

Fue estimada la diversidad específica de la familia Loricariidae (Siluriformes, Pisces) en las 10 provincias de la región San Martín (Amazonía peruana). Para la caracterización molecular fueron obtenidas las secuencias nucleotídicas del gen mitocondrial Citocromo $C$ Oxidasa sub unidad I (COI). El análisis filogenético de las secuencias confirmó la presencia de 16 especies, distribuidos en nueve géneros. Los valores de la riqueza observada y la riqueza esperada muestran a la provincia Picota como la de mayor riqueza (siete especies), contrariamente la provincia Rioja fue la que presentó la menor riqueza observada (una especie), seguida por la provincia El Dorado (dos especies). El análisis de componente principal (PCA) nos permitió observar la importancia que tiene la especie Chaetostoma sp. 1 en la provincia Rioja, así como Ancistrus sp. 2 para 
la provincia San Martín. Además nuestros resultados muestran que la especie más abundante en la región San Martín fue Chaetostoma sp. 1, mientras que la de menor abundancia fueron Aphanotorolus emarginatus y Chaetostoma sp. 3. La especie de mayor distribución fue Ancistrus sp. 2 encontrándose en seis provincias, seguida de las especies Chaetostoma stroumpoulos y Chaetostoma sp. 1 quienes estuvieron presentes en cinco provincias diferentes de la región San Martín. Las especies Pterygoplichthys pardalis, Aphanotorulus emarginatus, Chaetostoma sp. 3, Ancistrus sp. 1 y Farlowella smithi estuvieron restrictas cada una a solo una provincia. Las especies comerciales conocidas como carachama parda P. pardalis y carachama negra Hypostomus hemicochliodon fueron poco frecuentes en las capturas (seis y 11 individuos respectivamente), la primera estuvo restricta solo a la provincia de Picota, en tanto que la segunda fue encontrada en las provincias de Bellavista, Huallaga y Picota. Los resultados muestran que si bien la diversidad de especies de loricáridos no es tan diversa como en la selva baja, algunas especies de esta familia están bien distribuidas y son bastante abundantes en esta región.

PALABRAS CLAVES: Secuenciamiento nucleotídico, COI, peces, código de barras genético, carachama.

\title{
APPLICATION OF THE BARCODING FOR THE ESTIMATION OF THE SPECIFIC DIVERSITY OF THE LORICARIIDAE FAMILY (PISCES: SILURIFORMES) IN THE SAN MARTÍN REGION, PERUVIAN AMAZON
}

\begin{abstract}
The specific diversity of the Loricariidae family (Siluriformes, Pisces) was estimated in the 10 provinces of the San Martín region (Peruvian Amazon). For molecular characterization, the nucleotide sequences of the mitochondrial gene Cytochrome C Oxidase subunit I (COI) were obtained. The phylogenetic analysis of the sequences confirmed the presence of 16 species, distributed in nine genera. The values of observed wealth and expected wealth show the province of Picota as the richest (seven species), unlike the province of Rioja that presented the lowest observed wealth (one species), followed by the province of El Dorado (two species). The principal component analysis (PCA) allowed us to observe the importance of the species Chaetostoma sp. 1 in the province of Rioja, as well as in Ancistrus sp. 2 for the province of San Martin. In addition, our results show that the most abundant species in the San Martín region was Chaetostoma sp. 1,
\end{abstract}


while the one with the lowest abundance was Aphanotorolus emarginatus and Chaetostoma sp. 3. The species of greatest distribution was Ancistrus sp. 2 are found in six provinces, followed by the species Chaetostoma stroumpoulos and Chaetostoma sp. 1 who were present in five different provinces of the San Martin region. The species Pterygoplichthys pardalis, Aphanotorulus emarginatus, Chaetostoma sp. 3, Ancistrus sp. 1 and Farlowella smithi were restricted to a single province. The commercial species known as carachama parda P. pardalis and carachama negra Hypostomus hemicochliodon were rare in the catches (six and 11 individuals respectively), the first was limited only to the province of Picota, while the second was found in the provinces of Bellavista, Huallaga and Picota. The results show that although the diversity of loricariid species is not as diverse as in the lower jungle, some species of this family are well distributed and quite abundant in this region.

KEYWORDS: Nucleotide sequencing, COI, fish, genetic barcode, armored catfish. 


\section{INTRODUCCIÓN}

La región San Martín es recorrida por la red hidrográfica de la cuenca media del río Huallaga, que abarca áreas de Selva Alta y Baja de la Amazonía peruana (Guerra et al., 1999). En esta región y en el Neotrópico en general, después de los Characiformes, los Siluriformes son el grupo más importante de peces en cuanto al número de especies (Mori-Marín et al., 2012). Dentro de esta gran diversidad se encuentra la familia Loricariidae, distribuida en las aguas dulces de América del Sur y parte de América Central (Boeseman, 1968). Esta familia es la más rica en especies del orden Siluriformes, contiene 115 géneros y 936 especies válidas (Froese \& Pauly, 2018). En los últimos diez años se describieron 230 nuevas especies (Eschmeyer, 2017) y probablemente varios cientos de especies estén esperando ser descritas (Lujan et al., 2015). Los loricáridos presentan especies de pequeño y mediano porte, con una longitud estándar menor de 20 centímetros, y una longitud total de casi un metro en algunas especies (Lujan et al., 2010). Son especies muy requeridas por la acuariofilia internacional, exportados en grandes cantidades para el comercio internacional de peces ornamentales (Prang, 2007). Poseen importancia ecológica como reguladores de la dinámica de producción de nutrientes primarios en muchos ríos de Sudamérica, debido a las altas concentraciones de fosfato de calcio presentes en sus placas dérmicas (Vanni et al., 2002; Knoll et al., 2009).

A pesar de su increíble diversidad específica, morfología única e importancia económica y ecológica poco se sabe todavía de este grupo de peces. Hasta el momento la mayor parte de la información está relacionada a inventarios rápidos que no cubren toda la diversidad específica del grupo. Aspectos relacionados a su biología, fisiología y ecología son todavía muy limitados (Lujan et al., 2015), incluyendo aspectos de genética y caracterización molecular. Estudios genéticos han demostrado que la mayor parte de la diversificación específica de la ictiofauna neotropical ocurrió recientemente, por lo que la taxonomía e identificación molecular de las especies es un gran desafío (Pereira et al., 2013). En el año 2003, Hebert et al. propusieron un método para identificar individuos en base a la caracterización de sectores específicos y estandarizados del genoma (barcoding), esta técnica de identificación molecular de especies tiene el potencial para una evaluación rápida y precisa en la identificación específica (Wong et al., 2011). Actualmente el código de barras (barcoding) vienesiendousado exitosamentepara la identificación de individuos de los diferentes taxa a nivel de especie, además tiene una vasta aplicación en diferentes campos de la biología, con probada capacidad para diferenciar especies relacionadas, estudios que van desde ciencias forenses (Dawnay et al., 2007) identificación de larvas de peces (Ko et al., 2013, García-Dávila et al., 2015), hasta subproductos de peces y otros (García-Dávila et al., 2017). En este sentido el presente trabajo tuvo como objetivo identificar molecularmente mediante el secuenciamiento del gen COI (barcoding) los especímenes de la familia Loricariidae muestreados en las 10 provincias de la región de San Martín.

\section{MATERIALES Y MÉTODOS}

\section{COLECCIÓN DE ESPECÍMENES}

Fueron colectados un total de 170 especímenes de la familia Loricariidae provenientes de las diez provincias de la región San Martín (tres puntos por provincia, Figura 1). Los especímenes capturados fueron codificados y fotodocumentados in situ. Para el análisis molecular, los especímenes fueron conservados en alcohol al 96\% y enviados 


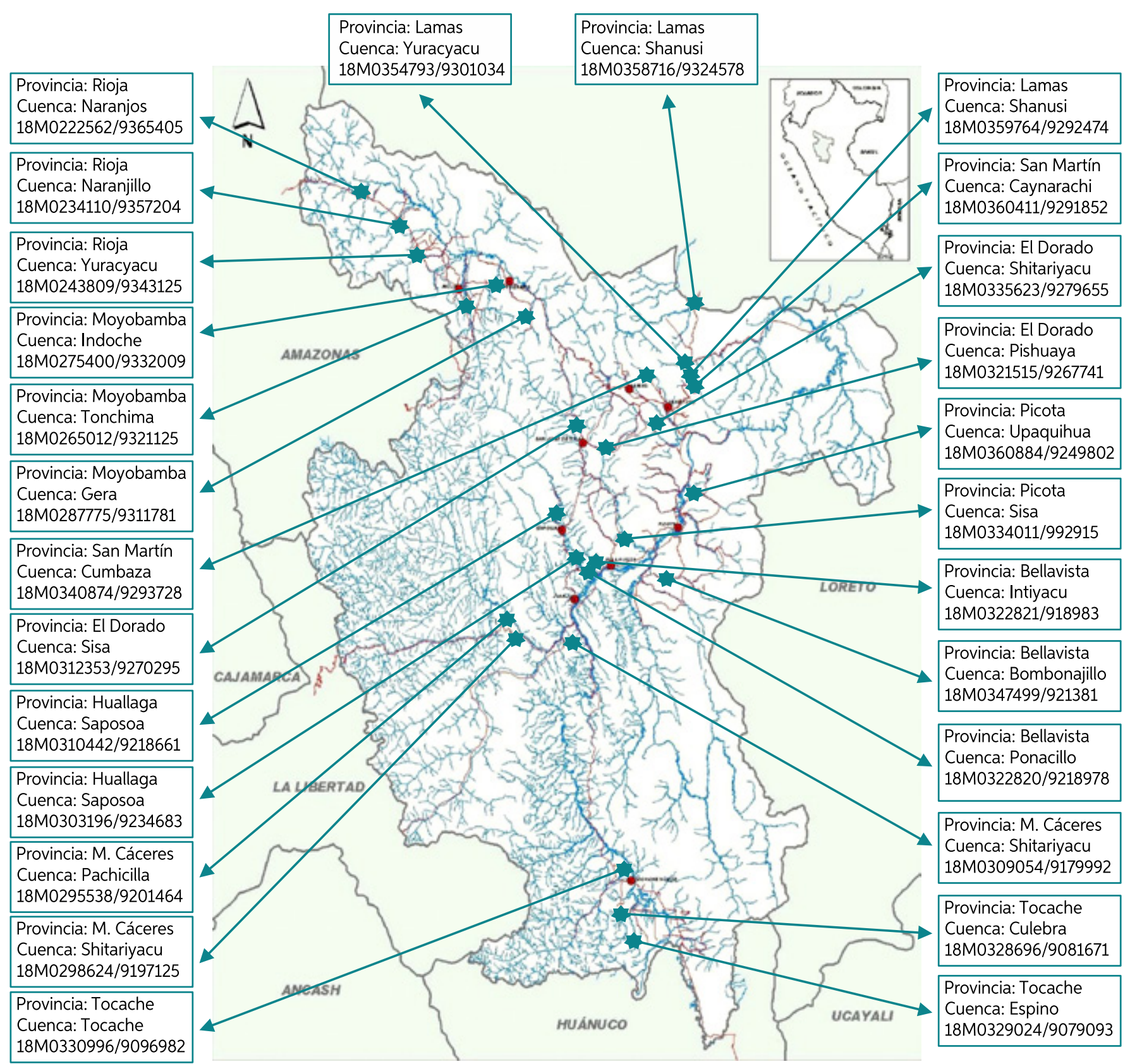

Figura 1. Mapa de la red hidrográfica de la región San Martín, indicando los puntos de colecta por provincia, con sus coordenadas geográficas. 
al Laboratorio de Biología y Genética MolecularLBGM del Instituto de Investigaciones de la Amazonía Peruana-IIAP.

\section{EXTRACCIÓN, AMPLIFICACIÓN Y SECUENCIAMIENTO NUCLEOTÍDICO DE ADN} La extracción de ADN fue realizada a partir de $100 \mathrm{mg}$ de tejido muscular conservado en alcohol al 96\%, mediante el protocolo CTAB (Doyle \& Doyle, 1987). El gen citocromo $C$ oxidasa sub unidad I (COI, 576 pb) fue amplificado utilizando los primers Fish F1 5'-TCA ACC AAC CAC AAA GAC ATT GGC AC-3' y Fish R1 5'-TAG ACT TCT GGG TGG CCA AAG AAT CA-3' (Hubert et al., 2008). La amplificación vía PCR fue realizada en un volumen final de $15 \mu$ conteniendo 6,78 $\mu \mathrm{l}$ de agua ultra pura, $3 \mu \mathrm{l}$ de Buffer $5 \mathrm{x}, 0,9 \mu \mathrm{l}$ de $\mathrm{MgCl}_{2}(25 \mathrm{mM}), 0,6 \mu \mathrm{l}$ de cada primer $(10 \mu \mathrm{M})$, 1,5 $\mu \mathrm{l}$ del mix de dNTP (2 mM), 0,12 $\mu \mathrm{l}(5 \mathrm{U} / \mathrm{ul})$ de Taq DNA polimerasa (Promega) y 1,5 $\mu$ l (100 $\mathrm{ng} / \mu \mathrm{l}$ ) de ADN molde. Las condiciones de PCR fueron de $94{ }^{\circ} \mathrm{C}$ durante $2 \mathrm{~min}, 35$ ciclos de $94^{\circ} \mathrm{C}$ durante $30 \mathrm{~s}, 54^{\circ} \mathrm{C}$ durante $40 \mathrm{~s}, \mathrm{y} 72^{\circ} \mathrm{C}$ durante $1 \mathrm{~min}$, con una extensión final a $72{ }^{\circ} \mathrm{C}$ durante 10 minutos. Los productos de PCR del gen COI fueron secuenciados utilizando los mismos primers de la amplificación en un analizador genético 3130XL (Applied Biosystems).

\section{ANÁLISIS DE DATOS}

Las secuencias obtenidas fueron editadas usando Bioedit versión 7.2.6 (Hall, 1999) y alineadas con el programa de alineamiento múltiple ClustalW (Thompson et al., 1994). Luego fueron comparadas con secuencias del GenBank. El número de sitios conservados, sitios variables, sitios informativos de parsimonia y singleton fueron obtenidos con el software MEGA 5 (Kumar et al., 2008). El número de haplotipos así como la diversidad haplotípica fueron obtenidos con el software DNAsp v.5.00 (Librado \& Rozas, 2009).
La determinación de la identidad genérica y específica de loricáridos fue realizada mediante tres vías: i) identificación taxonómica, ii) comparación de bases con otras secuencias depositadas en el GenBank (Sistema BLAST) y iii) establecimiento de las relaciones filogenéticas mediante un dendograma de haplotipos, para lo cual se seleccionó primero el modelo de evolución nucleotídica de entre 24 posibles modelos evolutivos de acuerdo con los valores del Criterio de Información Akaike (AIC) (Akaike, 1973). Para este trabajo el mejor modelo evolutivo fue TN93 + G (Tamura \& Nei, 1993), a partir del cual se construyó un dendrograma de los haplotipos. La identidad molecular de las especies fue determinada a través de la relación filogenética de la secuencia del haplotipo con 10 secuencias de COI de loricáridos obtenidas del GenBank (Figura 2), El dendrograma fue construido bajo el criterio de Máxima Verosimilitud (ML) (Felsenstein, 1981), tanto éste como el modelo de evolución nucleotídica fueron generados con ayuda del software MEGA 5 (Kumar et al., 2008). Después de la identificación molecular de los individuos, se estimó la riqueza observada y riqueza esperada con ayuda del software Past v.3.0 y el gráfico de dicha riqueza se elaboró con SigmaPlot v.11.0. El análisis de componente principal (PCA) se obtuvo con el software Comunity Analysis Package (CAP) v.4.0.

\section{RESULTADOS Y DISCUSIÓN}

\section{APLICACIÓN DEL BARCODING EN LA IDENTIFICACIÓN DE ESPECIES}

Se logró corroborar la identidad de los nueve géneros de loricarideos encontrados en la región de San Martín, mediante la herramienta de búsqueda alineamiento básico local (BLAST) y de sus relaciones filogenéticas en un dendrograma 
de máxima Verosimilitud (árbol de haplotipos). Solo cuatro de los 16 grupos genéticos mostrados en elárbol filogenético de haplotipos pudieron ser identificados a nivel específico con un porcentaje de identidad elevado ( $98 \%$ y 99\%), estas cuatro especies fueron también corroboradas mediante análisis morfológico (Tabla 1). Estudios anteriores sobre diversidad íctica en la región San Martín estaban enfocados solo en caracteres morfologicos (Maco, 2005; Meza, 2014), lo cual llevaba muchas veces a incluir individuos de especies diferentes morfológicamente dentro de una misma especie taxonomica, debido a su gran parecido morfológico; o por el contrario, considerar individuos de una misma especie como si se trataran de diferentes especies. En nuestro trabajo no logramos identificar a todos los individuos a nivel específico, esto se debe a que los loricarideos son un grupo muy complejo, con pequeñas diferencias entre sus especies, lo cual amerita la identificación por personal altamente especializado en el grupo, o en su defecto podría deberse a especies todavía no descritas por la ciencia y de las cuales no existe claves taxonómicas.

Dentro de los géneros Chaetostoma y Ancistrus que presentaron mayor diversidad de especies (cuatro y tres, respectivamente) solo fue posible identificar una solo especie en cada género $(C$. stroumpoulos para Chaetostoma y A. bufonius). Éstos géneros agrupan un complejo críptico de especies, muchas veces con distribución muy restringida (Eigenman \& Allen, 1942), por lo que es difícil su identificación a nivel específico, incluso Salcedo (2006) menciona que las especies $C$. changae, C. stroumpoulos y C. daidalmatos son especies simpátricas que habitan en la cuenca alta del río Huallaga, esto nos hace suponer que nuestras especies de Chaetostoma no identificadas podrían tratarse

Tabla 1. Porcentaje de identidad y número de accesión de las secuencias del BLAST que coinciden con las del presente trabajo.

\begin{tabular}{|c|c|c|c|c|}
\hline $\mathbf{N}^{\circ}$ & $\begin{array}{l}\text { ESPECIE IDENTIFICADA } \\
\text { TAXONÓMICAMENTE }\end{array}$ & ESPECIE SEGÚN EL BLAST & $\begin{array}{c}\% \text { DE } \\
\text { IDENTIDAD } \\
\text { BLAST }\end{array}$ & $\begin{array}{c}\text { NÚMERO DE } \\
\text { ACCESIÓN BLAST }\end{array}$ \\
\hline 01 & Peckoltia sp. & Peckoltia furcata & 96 & KX087180.1 \\
\hline 02 & Aphanotorulus emarginatus & Aphanotorulus emarginatus & 99 & KT239019.1 \\
\hline 03 & Aphanotorulus unicolor & Aphanotorulus emarginatus & 94 & KT239019.1 \\
\hline 04 & Pterygoplichthys pardalis & Pterygoplichthys pardalis & 99 & KT239016.1 \\
\hline 05 & Hypostomus cochliodon & Hypostomus cochliodon & 98 & HM376401.1 \\
\hline 06 & Hypostomus hemicochliodon & Hypostomus ancistroides & 96 & GU701723.1 \\
\hline 07 & Lasiancistrus heteracanthus & Lasiancistrus schomburgkii & 97 & KP772579.1 \\
\hline 08 & Ancistrus bufonius & Ancistrus sp. (1) & 95 & KP960569.1 \\
\hline 09 & Ancistrus sp. 1 & Ancistrus sp. (2) & 94 & KP960569.1 \\
\hline 10 & Ancistrus sp. 2 & Ancistrus sp. (3) & 95 & KP960569.1 \\
\hline 11 & Chaetostoma sp. 1 & Chaetostoma sp. (1) & 89 & EU359410.1 \\
\hline 12 & Chaetostoma sp. 2 & Chaetostoma sp. (2) & 89 & EU359410.1 \\
\hline 13 & Chaetostoma sp. 3 & Chaetostoma sp. (3) & 93 & EU359410.1 \\
\hline 14 & Chaetostoma stroumpoulos & Chaetostoma sp. (4) & 96 & EU359410.1 \\
\hline 15 & Farlowella smithi & Farlowella smithi & 98 & KT952444.1 \\
\hline 16 & Loricaria sp. & Loricaria cataphracta & 95 & KX087174.1 \\
\hline
\end{tabular}




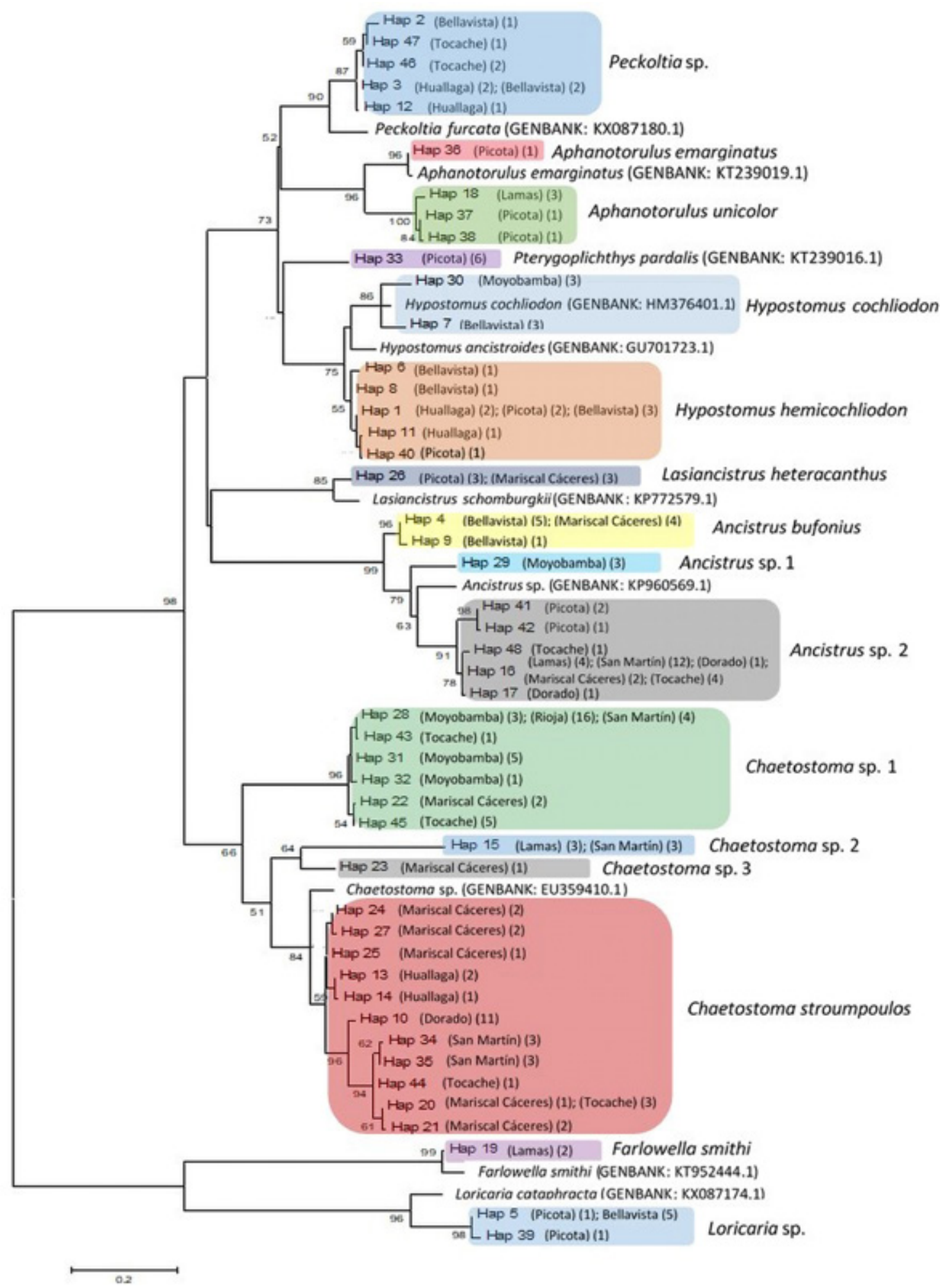

Figura 2. Árbol consenso de Máxima Verosimilitud de Haplotipos de Loricáridos de la región San Martín, modelo evolutivo TN93 + G. Entre los paréntesis la provincia y el número de individuos por provincia (cuadros a color). En los nodos, valores de bootstrap (500 repeticiones) mayores a 50. Además se indica el número de accesión de las secuencias obtenidas del Genbank. 
de las mencionadas por Salcedo, 2006. GarcíaDávila et al. (2015) y Moreira et al. (2017) en sus investigaciones también obtuvieron secuencias del género Ancistrus, no logrando identificarlos a nivel de especie.

El BLAST logró identificar a las especies encontradas del género Hypostomus como $H$. cochliodon e $H$. ancistroides, este último fue identificado taxonómicamente en base a caracteres morfológicos como $H$. hemicochliodon, las diferencias entre la identificación del BLAST y morfológica en la determinación de la especie se debe a que en el GenBank no se encuentra depositada ninguna secuencia de la especie $H$. hemicochliodon con el gen mitocondrial Citocromo C Oxidasa sub unidad I (COI), es por ello que al momento de realizar la comparación de bases nucleotídicas, el BLAST identifica a nuestro individuo con la secuencia disponible más próxima, en este caso con la especie $H$. ancistroides. Similar caso se pudo observar entre las especies Aphanotorulus emarginatus (según el BLAST) y Aphanotorulus unicolor (identificación taxonómica), Lasiancisturs schomburgkii (BLAST) y Lasiancistrus heteracanthus (identificación taxonómica) (Tabla 1).

\section{DIVERSIDAD ESPECÍFICA DE LORICARIIDAE A NIVEL DE LA REGIÓN SAN MARTÍN}

Nuestros resultados muestran (Figura 2) en la región de San Martin la presencia de nueve de los 36 géneros reportados para la Amazonia peruana (Ortega et al., 2012). En la figura 2 también podemos observar nueve grupos genéticos identificados a nivel de especie y siete que solo pudimos identificar a nivel de género. Los géneros más diversos fueron Chaetostoma y Ancistrus (4 y 3 especies, respectivamente), en tanto que los menos diversos fueron Peckoltia, Loricaria y Farlowella (con una especie cada una de ellas). La diversidad específica encontrada dentro de estos géneros es concordante a su naturaleza, los géneros con mayor número de taxa son aquellas cuyas especies están mejor adaptadas a habitar cuerpos de agua más torrentosos y en mayor altitud, como es el caso del género Chaetostoma que agrupa especies que se distribuyen preferencialmente en cuerpos de agua de selva alta. Al igual que las especies del género Ancistrus, como A. bufonius que es exclusivo de tierras altas, esto nos hace suponer que las otras dos restantes pudieran tener el mismo comportamiento, aunque algunas especies dentro de este género se distribuyen también en selva baja (Sánchez et al., 2012). Los géneros Loricaria y Farlowella fueron colectados en cuerpos de agua de tierras bajas colindante a la región Loreto, región en donde estos géneros son más diversos. En el caso de la especie del genero Peckoltia, según la lista anotada de Ortega et al. (2012) hay cinco especies reportadas para el Perú, todas ellas registradas en selva baja, lo que nos hace suponer que nuestro registro se trataría de una especie distinta, porque ella habita cuerpos de agua de tierras altas en la región de San Martin.

Ancistrus sp. 2 fue la especie que presentó la mayor distribución geográfica, encontrándose en seis provincias de las 10 provincias analizadas (El Dorado, Lamas, Mariscal Cáceres, Picota, San Martín y Tocache), seguida por C. stroumpoulos y Chaetostoma sp. 1 (presentes en cinco de las diez provincias), estas dos últimas especies poseen los mayores porcentajes de representatividad a nivel regional (18.9\% y $21.8 \%$, respectivamente) frente a un $16.5 \%$ que presenta Ancistrus sp2 (Tabla 2). Si bien C. stroumpoulos estuvo presente en las provincias de Huallaga, Mariscal Cáceres, San Martín, Tocache y El Dorado, pero en esta última fue más numerosa (34\% del total de individuos capturados de esta especie). En cambio la especie Chaetostoma sp. 1 fue dominante en las colectas de la provincia Rioja (43\% del total de individuos capturados de esta especie), pero fue registrado también en las provincias Mariscal 
Tabla 2. Porcentaje de representatividad por especie en la región San Martín

\begin{tabular}{|c|c|c|c|}
\hline \multirow{2}{*}{ GÉNERO } & ESPECIE & $\begin{array}{c}\text { Nro. de individuos por } \\
\text { especie }\end{array}$ & $\begin{array}{c}\text { \% de representatividad a } \\
\text { nivel regional }\end{array}$ \\
\hline Peckoltia & Peckoltia sp. & 9 & 5.3 \\
\hline \multirow{2}{*}{ Aphanotorulus } & A. emarginatus & 1 & 0.6 \\
\cline { 2 - 4 } & A. unicolor & 5 & 2.9 \\
\hline \multirow{2}{*}{ Pterygoplichthys } & P. pardalis & 6 & 3.5 \\
\hline \multirow{2}{*}{ Hypostomus } & H. cochliodon & 6 & 3.5 \\
\hline Lasiancistrus & H. hemicochliodon & 11 & 6.5 \\
\hline \multirow{3}{*}{ Ancistrus } & L. heteracanthus & 6 & 3.5 \\
\cline { 2 - 4 } & A. bufonius & 10 & 1.9 \\
\cline { 2 - 4 } & Ancistrus sp. 1 & 3 & 16.5 \\
\cline { 2 - 4 } & Ancistrus sp. 2 & 28 & 21.8 \\
\hline \multirow{3}{*}{ Chaetostoma } & Chaetostoma sp. 1 & 37 & 3.5 \\
\cline { 2 - 4 } & Chaetostoma sp. 2 & 6 & 0.6 \\
\cline { 2 - 4 } & Chaetostoma sp. 3 & 1 & 18.9 \\
\cline { 2 - 4 } & C. stroumpoulos & 32 & 1.2 \\
\hline Farlowella & F. smithi & 2 & 4.1 \\
\hline Loricaria & Loricaria sp. & 7 & 100 \\
\hline \multicolumn{2}{|c|}{ TOTAL DE INDIVIDUOS } & 170 & \\
\hline
\end{tabular}

Tabla 3. Diversidad y número de especies de loricáridos identificados por provincia

\begin{tabular}{|c|c|c|c|c|c|c|c|c|c|c|c|}
\hline \multirow[b]{2}{*}{ GÉNERO } & \multirow[b]{2}{*}{ ESPECIE } & \multicolumn{10}{|c|}{ PROVINCIA } \\
\hline & & $\begin{array}{l}\frac{\pi}{n} \\
\frac{\sqrt[n]{0}}{\bar{N}} \\
\infty\end{array}$ & $\begin{array}{l}0 \\
\frac{0}{0} \\
\overline{0} \\
\frac{0}{0} \\
\bar{w}\end{array}$ & 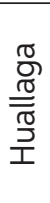 & 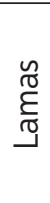 & 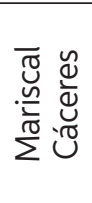 & 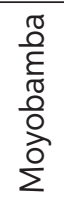 & $\begin{array}{l}\frac{T}{0} \\
\stackrel{\underline{U}}{\alpha}\end{array}$ & $\frac{\frac{\sigma}{\alpha}}{\frac{\alpha}{\alpha}}$ & 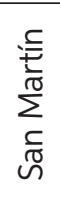 & 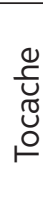 \\
\hline Peckoltia & Peckoltia sp. & 3 & & 3 & & & & & & & 3 \\
\hline \multirow{2}{*}{ Aphanotorulus } & A. emarginatus & & & & & & & 1 & & & \\
\hline & A. unicolor & & & & 3 & & & 2 & & & \\
\hline Pterygoplichthys & P. pardalis & & & & & & & 6 & & & \\
\hline \multirow{2}{*}{ Hypostomus } & H. cochliodon & 3 & & & & & 3 & & & & \\
\hline & H. hemicochliodon & 5 & & 3 & & & & 3 & & & \\
\hline Lasiancistrus & L. heteracanthus & & & & & 3 & & 3 & & & \\
\hline \multirow{3}{*}{ Ancistrus } & A. bufonius & 6 & & & & 4 & & & & & \\
\hline & Ancistrus sp. 1 & & & & & & 3 & & & & \\
\hline & Ancistrus sp. 2 & & 2 & & 4 & 2 & & 3 & & 12 & 5 \\
\hline \multirow{4}{*}{ Chaetostoma } & Chaetostoma sp. 1 & & & & & 2 & 9 & & 16 & 4 & 6 \\
\hline & Chaetostoma sp. 2 & & & & 3 & & & & & 3 & \\
\hline & Chaetostoma sp. 3 & & & & & 1 & & & & & \\
\hline & C. stroumpoulos & & 11 & 3 & & 8 & & & & 6 & 4 \\
\hline Farlowella & F. smithi & & & & 2 & & & & & & \\
\hline \multirow{2}{*}{$\frac{\text { Loricaria }}{\text { TOTAL DE }}$} & Loricaria sp. & 5 & & & & & & 2 & & & \\
\hline & INDIVIDUOS & 22 & 13 & 9 & 12 & 20 & 15 & 20 & 16 & 25 & 18 \\
\hline
\end{tabular}

Los números indican la cantidad de individuos secuenciados 
Cáceres, Moyobamba, San Martín y Tocache. Por el contrario las especies Aphanotorulus emarginatus, Chaetostoma sp. 3, Ancistrus sp. 1, Farlowella smithi y Pterygoplichthys pardalis, estuvieron restrictas cada una de ellas a solo una provincia (Tabla 3). La última especie conocida localmente como carachama negra, fue poco abundante en toda la región San Martín (4\% del total de individuos capturados en la región), ver Tabla 2. Al contrario la especie Hypostomus hemicochliodon (especie comercial conocida como carachama parda), mostró una distribución geográfica más amplia encontrándose en las provincias Bellavista, Huallaga y Picota (Tabla $2)$, esta especie tiene igual importancia que P. pardalis carachama negra, para el consumo humano.

\section{DIVERSIDAD ESPECÍFICA POR PROVINCIA}

BELLAVISTA: Los 22 individuos secuenciados mostraron la presencia de cinco especies en esta provincia. Mediante secuencia nucleotídica solo pudo ser identificado a nivel de especie Hypostomus cochliodon (tres individuos, BLAST con 98\% de afinidad); a nivel de genero ocho individuos: tres como Peckoltia sp. (BLAST con 96\% de afinidad) y cinco como Loricaria sp. (BLAST con 95\% de afinidad). Los individuos restantes fueron identificados como $H$. hemicochliodon y seis como Ancistrus bufonius mediante la taxonomía morfológica (Tabla 1).

EL DORAD0: Los 13 individuos secuenciados pertenecieron solo a dos especies. Mediante el BLAST identificamos a nivel de genero a Chaetostoma sp. y Ancistrus sp.; Sin embargo mediante la taxonomía se pudo determinar que los individuos del género Chaetostoma pertenecen a la especie C. stroumpoulos. Al adicionar las secuencias depositadas en el GenBank a nuestro dendrograma de haplotipos, observamos que nuestros individuos son distantes a los del GenBank (solo un 95\% de afinidad), quedando los individuos del género Ancistrus como Ancistrus sp. 2 (Tabla 1).

HUALLAGA: Secuenciamos nueve individuos, el BLAST no logró identificar a ningún individuo a nivel específico, pero mediante la identificación taxonómica se determinó que tres individuos pertenecen a la especie $H$. hemicochliodon, tres individuos son de la especie Peckoltia sp. y tres de la especie $C$. stroumpoulos, todo esto se confirmó al incorporar las secuencias depositas en el GenBank (BLAST) a nuestro árbol de haplotipos, donde se observó claramente que nuestros individuos son especies diferentes a las reportadas en el Genbank (Figura 2).

LAMAS: Secuenciamos un total de 12 individuos, el BLAST solo identificó a las especie Farlowella smithi, con un porcentaje de similaridad de $98 \%$ (Tabla 1) y a los géneros Mediante la taxononía se logró identificar a la especie Aphanotorulus unicolor, además confirmó lo identificado mediante BLAST con respecto a los dos individuos de la especie Farlowella smithi. Además el BLAST identificó a los géneros Chaetostoma y Ancistrus, observamos que tres de nuestros individuos secuenciados fueron identificados como Chaetostoma sp. 2 y cuatro como Ancistrus sp. 2 (Tabla 3).

MARISCAL CÁCERES: En total se obtuvieron 20 individuos secuenciados. El BLAST no logró identificar a nivel específico a ningún individuo, pero si a nivel de género. Con la identificación taxonómica se logró identificar a las especies L. heteracanthus (tres individuos), ocho individuos como la especie C. stroumpoulos y cuatro individuos como A. bufonius. Al adicionar las secuencias de Genbank a nuestro árbol de 
haplotipos observamos que nuestros individuos de Chaetostoma y Ancistrus son distantes a éstas secuencias, quedando dos individuos como Chaetostoma sp. 1, uno como Chaetostoma sp. 3 y dos como Ancistrus sp. 2.

MOYOBAMBA: En total se secuenciaron 15 individuos pertenecientes a tres especies, Los géneros identificados mediante el BLAST fueron Chaetostoma, Ancistrus, e Hypostomus. Sin embargo, nuevamente el BLAST no logró determinar las especies de los nueve individuos de Chaetostoma, quedando como Chaetostoma sp. 1, ni los tres individuos de Ancistrus, quedando como Ancistrus sp. 1; pero si determinó a los tres individuos del género Hypostomus como la especie H. cochliodon (con un $98 \%$ de porcentaje de identidad, Tabla 1). Con la identificación taxonómica los géneros Chaetostoma y Ancistrus se mantuvieron como sp. 1.

PICOTA: Se obtuvo las secuencias de 20 individuos. Fue la provincia con mayor diversidad específica. Encontramos 6 géneros: Hypostomus, Pterygoplichthys, Aphanotorulus, Lasiancistrus, Ancistrus y Loricaria, distribuidos en siete especies. El BLAST asignó un porcentaje de identidad específica confiable solo a los individuos de los géneros Pterygoplichthys y Aphanotorulus, identificándolos como las especies P. pardalis (99 $\%$ de porcentaje de identidad) y $A$. emarginatus (99\% de porcentaje de identidad, solo para un individuo), para el resto de individuos los porcentajes de identidad asignados por el BLAST no fueron confiables (menores a $98 \%$ ), identifican correctamente el género pero no la especie (Tabla 1). Taxonómicamente si fue posible identificar a nivel de especie a los géneros Hypostomus, Aphanotorulus, Lasiancistrus, quedando como $H$. hemicochliodon, A. unicolor y L. heteracanthus, respectivamente. Los tres individuos del género Ancistrus y los dos individuos del género Loricaria no pudieron ser identificados a nivel específico, quedando como Ancistrus sp. 2 y Loricaria sp. Todo lo descrito se evidencia al observar el árbol de haplotipos (Figura 2).

RIOJA: Esta fue la provincia menos diversa en el presente estudio, se encontró únicamente al género Chaetostoma, el BLAST no pudo determinar la especie de los 16 individuos secuenciados para esta provincia, quedando como Chaetostoma sp. 1. (Tabla 1).

SAN MARTÍN: Se obtuvieron 25 secuencias nucleotídicas pertenecientes a 2 géneros: Chaetostoma y Ancistrus. El BLAST al igual que en la provincia Rioja, no logró determinar la especie de los 13 individuos del género Chaetostoma, quedando cuatro individuos como Chaetostoma sp. 1, tres como Chaetostoma sp. 2, sin embargo mediante la identificación taxonómica se logró identificar a los seis individuos restantes como la especie C. stroumpoulos. Asimismo el BLAST tampoco logró determinar a nivel específico los 12 individuos del género Ancistrus (Tabla 1), quedando estos como Ancistrus sp. 2.

TOCACHE: Secuenciamos 18 individuos, los cuales pertenecieron a 3 especies distribuidas en 3 géneros. Los géneros identificados mediante el BLAST fueron Ancistrus, Chaetostoma y Peckoltia (cinco, diez y tres individuos, respectivamente). Sin embargo el BLAST no logró identificar a nivel específico a ningún individuo de esta provincia. Con ayuda de la identificación taxonómica se logró identificar a cuatro individuos del género Chaetostoma como la especie C. stroumpoulos, los seis restantes individuos de este género quedaron como Chaetostoma sp. 1 . Al adicionar a nuestro árbol de haplotipos (dendrograma) secuencias obtenidas del GenBank, se observó que nuestros tres individuos del género Peckoltia son diferentes a la especie obtenida del GenBank (Peckoltia 
furcata), quedando nuestros especímenes como Peckoltia sp.; similar caso se observó con nuestros cinco individuos del género Ancistrus, los cuales no pudieron ser identificados mediante el BLAST ni taxonómicamente, quedando como Ancistrus sp. 2 (Tabla 1).

\section{RIQUEZA OBSERVADA VERSUS RIQUEZA ESPERADA}

Los resultados muestran claramente que la provincia Picota presentó la mayor riqueza de especies (siete especies), seguida de cerca por las provincias Mariscal Cáceres y Bellavista (seis y cinco, respectivamente). Contrariamente la provincia Rioja fue la que presentó la menor riqueza observada (una especie), seguida por la provincia El Dorado, con dos especies. A pesar que la provincia Rioja presentó menor riqueza de especies, al mismo tiempo fue la provincia que evidenció la mayor dominancia de una especie (Chaetostoma sp. 1). Incluso Chaetostoma sp. 1 fue la especie más representativa porcentualmente en toda la región San Martín. El número de especies observadas al ser contrastada con el número de especies esperadas, nos mostró que ambas riquezas (observaday esperada) coinciden en cuanto a número de especies (Figura 3). Esto quiere decir que nuestras capturas durante todos los muestreos abarcaron con prácticamente todas las especies presentes en estas zonas geográficas. Estas igualdades entre la riqueza observada y la esperada nos dan a entender que los muestreos realizados para el presente trabajo son válidos, debido a que la riqueza observada supera más del $50 \%$ de la riqueza esperada, esto se puede apreciar en todas las provincias. Sin embargo, al tratarse de una zona con extensas áreas de bosques y ríos de corrientes rápidas

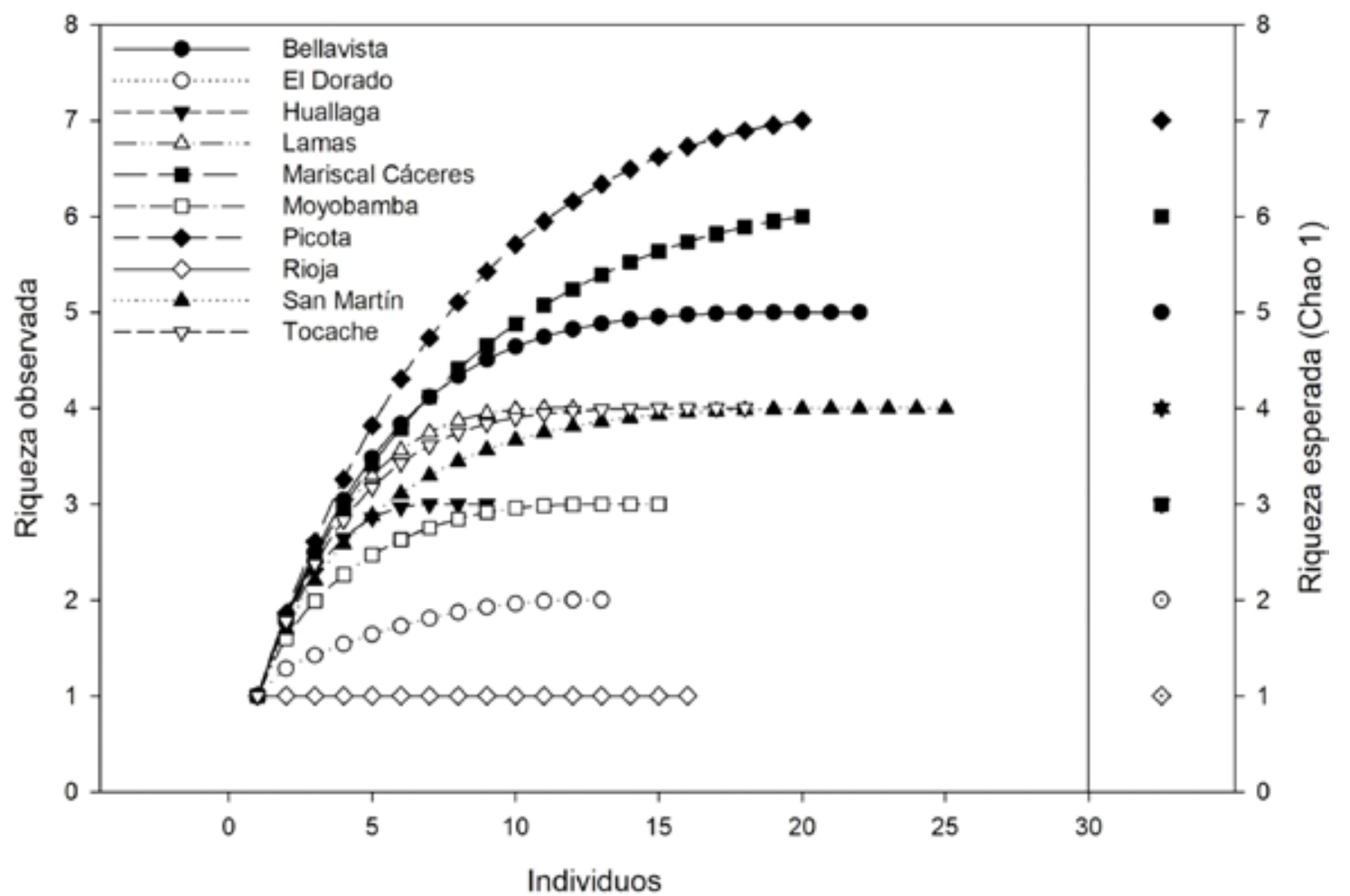

Figura 3. Gráfico de la riqueza observada y la riqueza esperada en las 10 provincias de la región San Martín. Eje horizontal indica número de individuos y los ejes verticales indican número de especies, izquierda especies encontradas y derecha especies esperadas. 
que en algunos casos penetran el bosque, lo cual contribuye a la disponibilidad de alimento y a la formación de un sinfín de hábitats para los peces, es muy probable que especies de menor abundancia o distribución geográfica estén pasando desapercibidas.

\section{DOMINANCIA DE LAS ESPECIES POR PROVINCIA}

El análisis de componente principal - PCA (Figura 4) muestra que las provincias presentan una o dos especies más representativas o dominantes en cada una de ellas. También se puede observar la dominancia de la especie Chaetostoma sp. 1 en las provincias Moyobamba y Rioja, siendo que en esta última provincia era la única especie que se capturo en esa área. Similar situación se observa en la provincia San Martín donde Ancistrus sp. 2 fue la especie dominante, mientras que $C$. stroumpoulos lo fue para las provincias Mariscal Cáceresy El Dorado (Figura 4). Solo en la provincia Bellavista no se observó una clara dominancia de alguna de las especies (la abundancia de especies en esta provincia osciló entre 13 a 23\%). Mientras que la provincia Picota siendo la más diversa en cuanto a especies, no presentó una dominancia por alguna de las especies encontradas en ella y a nivel regional las especies encontradas en Picota no son representativas. El análisis de componente principal (PCA) obtenido es explicativo, ya que la suma de los porcentajes de los ejes horizontal y vertical sobrepasan el 50\% (obtuvimos 66.73\%).

\section{APRECIACIÓN GLOBAL}

La eficiencia de los tres métodos empleados en la determinación de la especie (i) identificación taxonómica, ii) comparación de bases con otras secuencias depositadas en el GenBank (Sistema

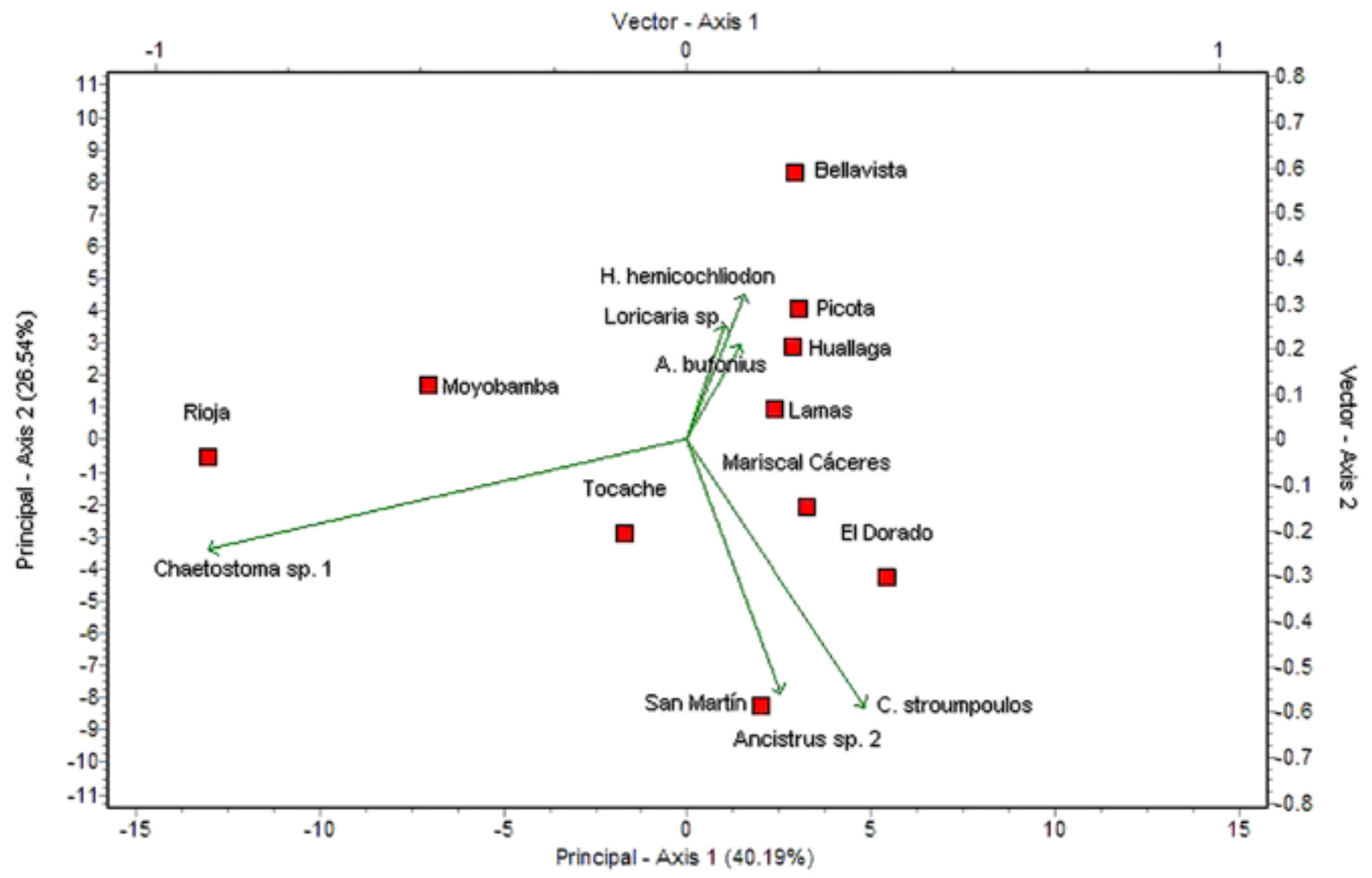

Figura 4. Análisis de componente principal (PCA) de las 10 provincias de la región San Martín. 
BLAST) y iii) elaboración de un dendograma de haplotipos) nos permite afirmar que son complementarios entre ellos. Los casos donde la identificación mediante el BLAST y la taxonomía no coincidían se deben principalmente a la falta de secuencias COI en el GenBank o a una mala identificación de la especie a partir de la secuencia del espécimen depositado en este banco de genes, pero la visualización de las relaciones filogenéticas de especies en el dendrograma ayudó a una mejor comprensión de estos casos.

Todos los géneros de loricáridos encontrados en la región San Martín son comercializadas en el mercado ornamental, pero dentro de estos existen dos especies que tiene potencial en la región dentro del mercado de consumo humano (carachama negra Pterygoplichthys pardalis y carachama parda Hypostomus hemicochliodon), pero estas especies presentan una reducida distribución en la región (Picota, Bellavista y Huallaga) y sus densidades son bajas en estos hábitats por lo que los podemos catalogarlas como especies no representativas en la región. Sin embargo su demanda en el mercado de consumo local es alto, por lo que se requiere urgentemente el desarrollo de un paquete tecnológico de producción en cautiverio. El IIAP a través de su filial San Martín, viene realizando trabajos experimentales en la reproducción en cautiverio de estas especies.

\section{BIBLIOGRAFÍA CITADA}

Akaike, H. 1973. Information theory and an extension of the maximum likelihood principle. In: Petrov, B.N., Csaki, F. (Eds.), Proceedings of the Second International Symposium on Information Theory, Akadémia Kiado, Budapest, 267-281.

Boeseman, M. 1968. The genus Hypostomus Lacepede, 1803, and its Surinam representatives (Siluriformes, Loricariidae) Zoologische. Verhandelingen, Leiden 99: 1-89. Dawnay, N.R.; Ogden, R.; McEwing, R.; Carvalho, G.R.; Thorpe, R.S. 2007. Validation of the barcoding gene COI for use in forensic genetic species identification. Forensic Science International, 173: 1-6.

Doyle, J.J.; Doyle, J.L. 1987. Isolation of plant DNA from fresh tissue. Focus, 12: 13-15.

Eigenmann, C.H.; Allen, W.R. 1942. Fishes of Western South America: I, The Intercordilleran and Amazonian Lowlands of Peru; II, The High Pampas of Peru, Bolivia, and Northern Chile; with a revision of the Peruvian Gymnotidae and of the Genus Orestias. The University of Kentucky, Lexington, Kentucky.

Eschmeyer, W.N. (Ed.), 2017. Catalog of Fishes: Family, Subfamily References. http:// researcharchive.calacademy.org/research/ ichthyology/catalog/SpeciesByFamily. asp\#Loricariidae. Online version Update 31 August 2017. Acceso: 10/09/2017.

Felsenstein, J.F. 1981. Evolutionary tree from DNA sequences: a maximum likelihood approach. Journal of Molecular Evolution, 17: 368-376.

Froese, R.; D. Pauly. Editors. 2018. FishBase. World Wide Web electronic publication. www. fishbase.org. Acceso: 14/12/2018.

García-Dávila, C.R.; Castro-Ruiz, D.; Renno, J.F.; Chota-Macuyama, W.; Carvajal-Vallejos, F.M.; Sánchez, H.; Angulo, C.; Nolorbe, C.; Alvarado, J.; Estivals, G.; Núñes-Rodríguez, J.; Duponchelle, F. 2015. Using barcoding of larvae for investigating the breeding seasons of pimelodid catfishes from the Marañon, Napo and Ucayali rivers in the Peruvian Amazon. Journal Applied Ichthyology, 31: 40 - 51.

García-Dávila, C.R.; Flores, M.; Pinedo, L.; Loyola, R.; Castro-Ruiz, D.; Angulo, C.; Mejía, E.; Sánchez, H.; García, A.; Chota, W.; Estivals, G.; Panduro, H.; Nolorbe, C.; Chuquipiondo, C.; Duponchelle, F.; Renno, J.F. 2017. Aplicación 
del barcoding al manejo y conservación de peces y sus subproductos en la Amazonía peruana. Folia Amazónica. 26(2): 195-204.

Guerra, H.; Ortega, H.; Maco, J.; Limachi, L.; Sánchez, H.; Ismiño, R.; García, A. 1999. Informe del Estudio: Evaluación del impacto de la introducción de especies exóticas en la cuenca del río Huallaga. Convenio Ministerio de Pesquería. Instituto de investigaciones de la Amazonía Peruana, Iquitos. 74pp.

Hall, T.A. 1999. BioEdit: a user-friendly biological sequence alignment editor and analysis program for Windows 95/98/NT. Nucleic Acids Symposium Series. 41: 95-98.

Hebert, P.D.N.; Cywinska, A.; Ball, S.L.; De Waard, J.R. 2003. Biological identifications through DNA barcodes. Proceedings Biological Sciences, 270: 313-321.

Hubert, N.; Torrico, J.P.; Bonhomme, F.; Renno, J.F. 2008. Species polyphyly and mtDNA introgression among three Serrasalmus sisterspecies. Molecular Phylogenetic Evolution, 46: 375-381.

Ko, H.L.; Wang, Y.T.; Chiu, T.S.; Lee, M.A.; Leu, M.Y.; Chang, K.Z. 2013. Evaluating the accuracy of morphological identification of larval fishes by applying DNA barcoding. Plos One, 8: 1: e53451

Knoll, L.B.; McIntyre, P.B.; Vanni, M.J.; Flecker, A.S. 2009. Feedbacks of consumer nutrient recycling on producer biomass and stoichiometry: separating direct and indirect effects. Oikos 118, 1732-1742.

Kumar, S.; Dudley, J.; Nei, M.; Tamura, K. 2008. MEGA: A biologist-centric software for evolutionary analysis of DNA and protein sequences. Briefings in Bioinformatics, 9: 299-306.

Librado, P.; Rozas, J. 2009. DnaSPv5: A software for comprehensive analysis of DNA polymorphism data. Bioinformatics, 25: 1451-452.
Lujan, N.K.; Armbruster, J.W.; Lovejoy, N.R; LópezFernández, H. 2015. Multilocus molecular phylogeny of the suckermouth armored catfishes (Siluriformes: Loricariidae) with a focus on subfamily Hypostominae. Molecular Phylogenetics and Evolution, 82: 269-288.

Lujan, N.K.; Hidalgo, M.; Stewart, D.J. 2010. Revision of Panaque (Panaque), with descriptions of three new species from the Amazon Basin (Siluriformes, Loricariidae). Copeia, 4: 676-704.

Maco, J. 2005. Zonificación Ecológica Económica de la Región San Martín. Hidrobiología. Gobierno Regional de San Martín. Instituto de Investigaciones de la Amazonía Peruana. Perú. $50 \mathrm{pp}$.

Meza, S.V. 2014. Ictiofauna y estado de conservación de los hábitats acuáticos entre Aucayacu y Tocache: Cuenca del río Huallaga (Huánuco-San Martín). Tesis de pre-grado, Universidad Nacional Mayor de San Marcos, Facultad de Ciencias Biológicas, Lima, Perú. 141pp.

Moreira, D.A.; Buckup, P.A.; Furtado, C.; Val, A.L.; Schama, R.; Parente, T.E. 2017. Reducing the information gap on Loricarioidei (Siluriformes) mitocondrial genomics. BMC Genomics. 18:345.

Mori-Marín, J.; Renno, J.F.; Carvajal-Vallejos, F.; Alcántara-Bocanegra, F.; Duponchelle, F.; García-Dávila C.R. 2012. Estudio comparativo de la variabilidad genética del zúngaro tigrinus - Brachyplatystoma tigrinum (Britski, 1981) y dos especies relacionadas de la familia Pimelodidae. Folia Amazónica, 21:87-95.

Ortega, H.; Hidalgo, M.; Trevejo, G.; Correa, E.; Cortijo, A.M.; Meza, V.; Espino, J. 2012. Lista anotada de los peces de aguas continentales del Perú: Estado actual del conocimiento, distribución, usos y aspectos de conservación. Ministerio del Ambiente, Dirección General 
de Diversidad Biológica-Museo de Historia Natural, UNMSM. 56pp.

Pereira, L.; Hanner, R.; Foresti, F.; Oliveira, C. 2013

Can DNA barcoding accurately discriminate megadiverse Neotropical freshwater fish fauna?. BMC Genetics, 14.

Prang, G. 2007. An industry analysis of the freshwater ornamental fishery with particular reference to the supply of Brazilian freshwater ornamentals to the UK market. Uakari, 3, 7-51. Sánchez, H.; Nolorbe, C.; García, C.; Ismiño, R.; Chota, W.; Tello, S.; García-Dávila, C. 2013. Diversidad y Abundancia de peces en los ríos Arabela y Curaray (Cuenca del rio Napo) en época de creciente y vaciante del 2012, Amazonia peruana. Folia Amazónica, 22(1-2): 43-57.

Salcedo, N. 2006. Two new species of Chaetostoma (Siluriformes: Loricariidae) from the Huallaga River in central Peru. Ichthyol. Explor. Freshwaters, 17(3):207-220.
Tamura, K.; Nei, M. 1993. Estimation of the number of nucleotide substitutions in the control region of mitochondrial DNA in humans and chimpanzees. Molecular Biology and Evolution, 10:512-526.

Thompson, J.D.; Higgins, D.G.; Gibson, T.J. 1994. Clustal W: improving the sensitivity of progressive multiple sequence alignment through sequence weighting, position specific gap penalties and weight choice. Nucleic Acids Research, 22:4673-4680.

Vanni, M.J.; Flecker, A.; Hood, J.M.; Headworth, J.L. 2002. Stoichiometry of nutrient recycling by vertebrates in a tropical stream: linking species identity and ecosystem processes. Ecology. Letters, 5: 285-293.

Wong, L.L.; Peatman, E.; Lu, J.; Kucuktas, H.; He, S.; Zhou, C.; Na-nakorn, U.; Liu, Z. 2011. DNA Barcoding of Catfish: Species Authentication and Phylogenetic Assessment. Plos one 6(3):e17812.

Recibido: 22 de mayo de 2018 Aceptado para publicación: 11 de julio de 2018 


\section{ANEXO: FOTOS DE LAS ESPECIES DE LORICÁRIDOS ENCONTRADAS}

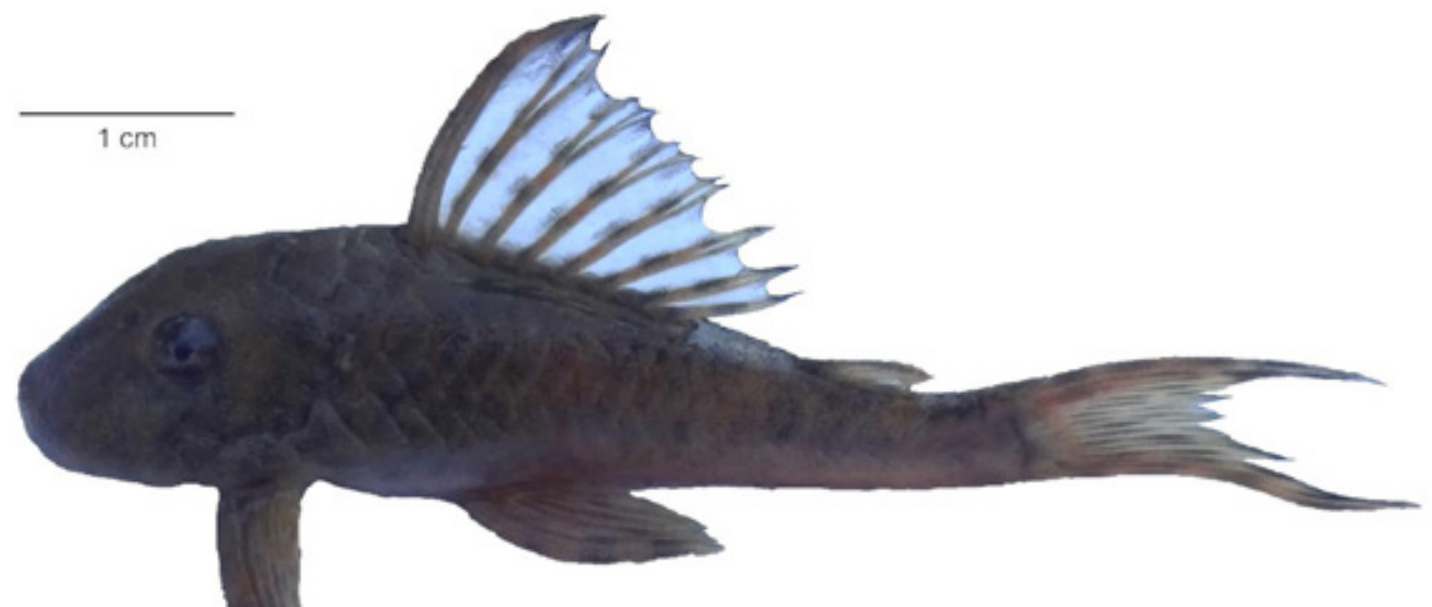

Peckoltia sp.

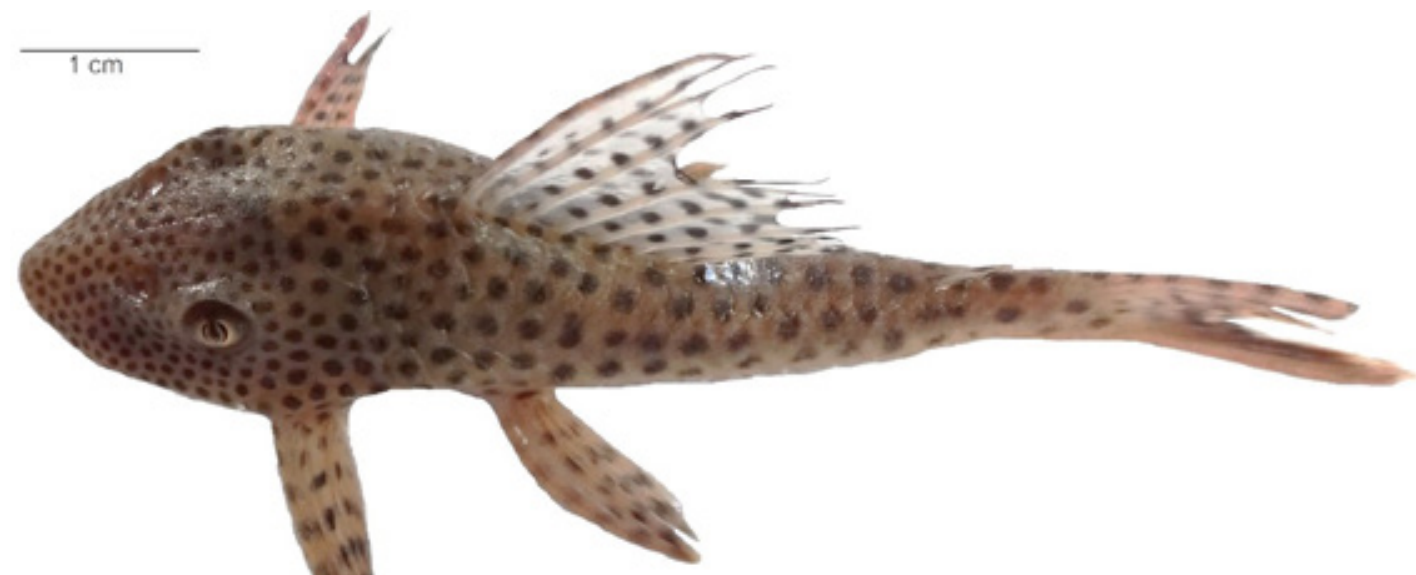

Aphanotorulus emarginatus

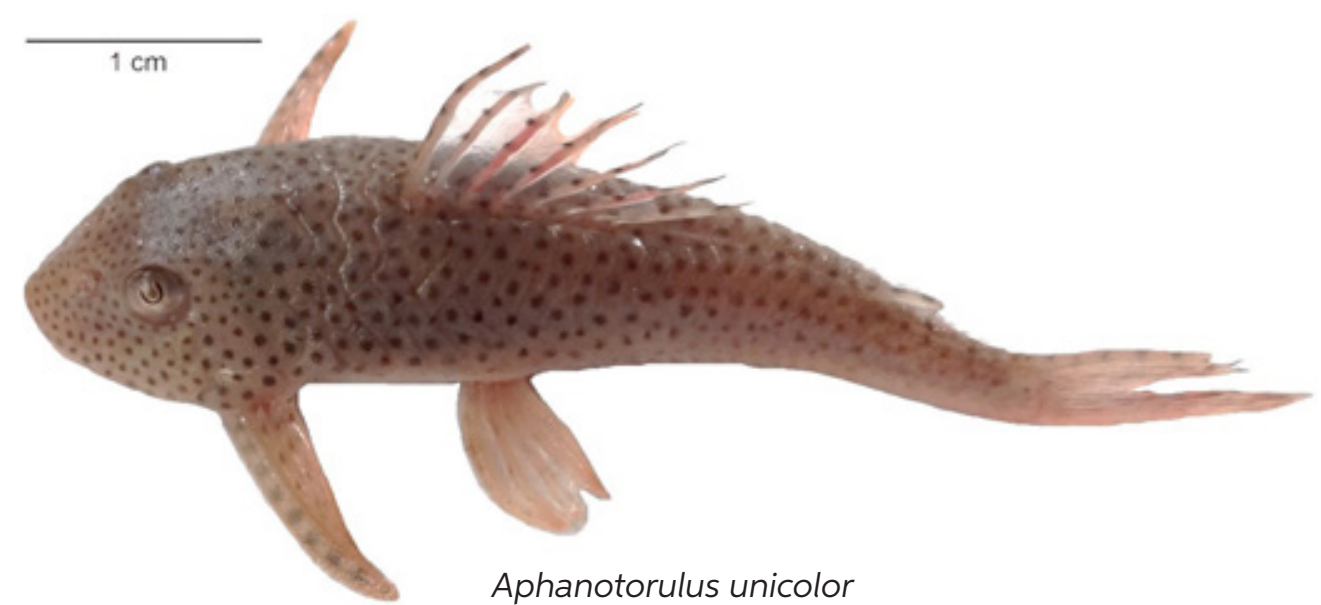



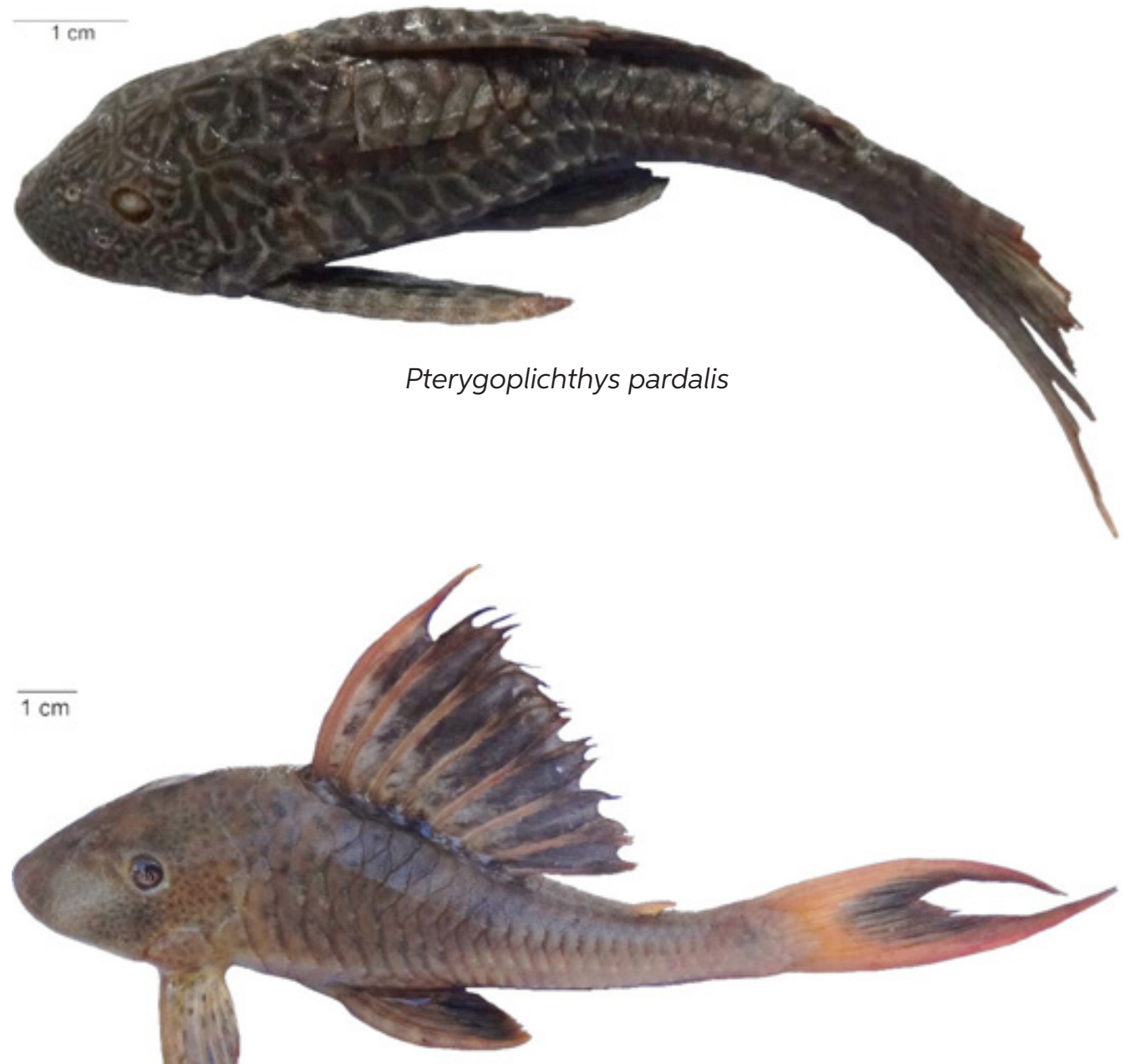

Hypostomus cochliodon

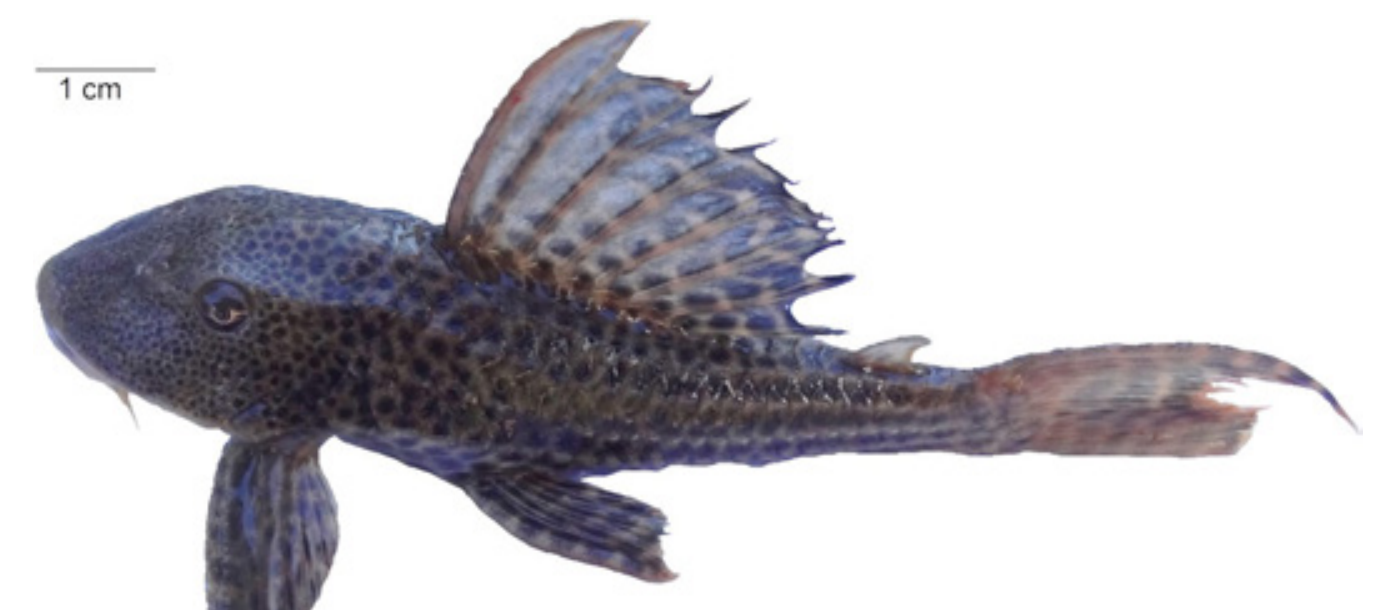

Hypostomus hemicochliodon 
FOLIA
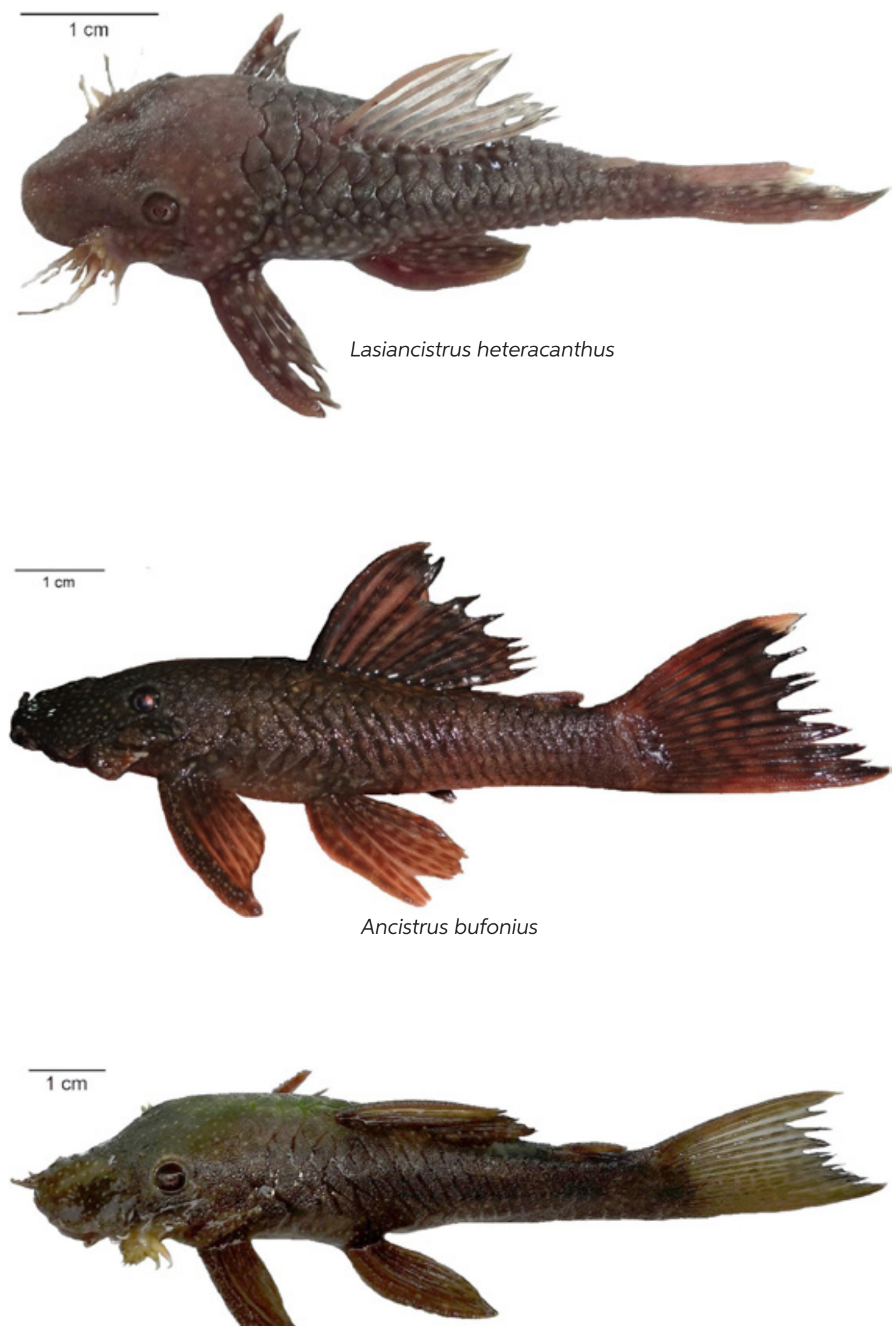

Ancistrus sp. 1 

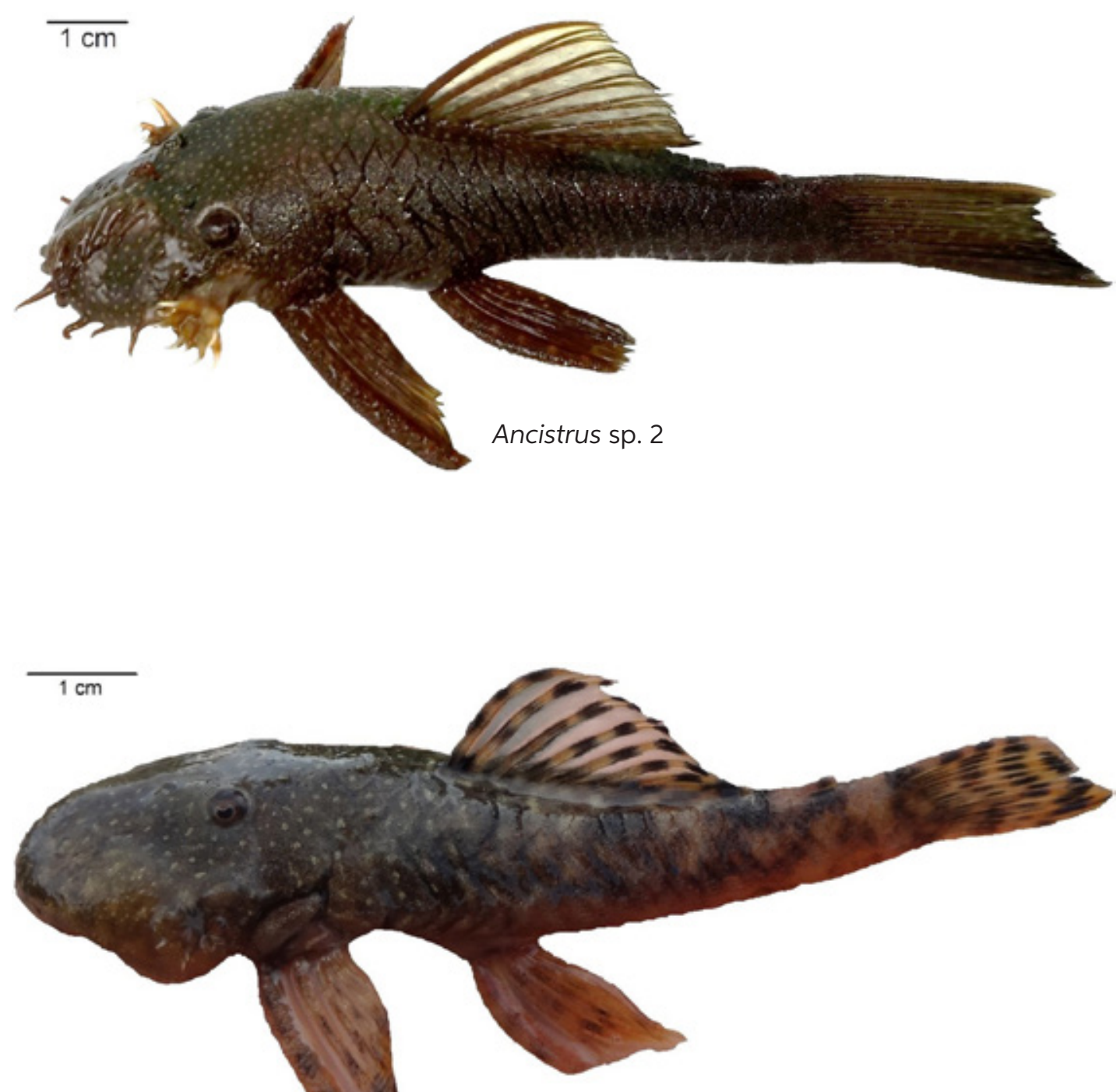

Chaetostoma sp. 1

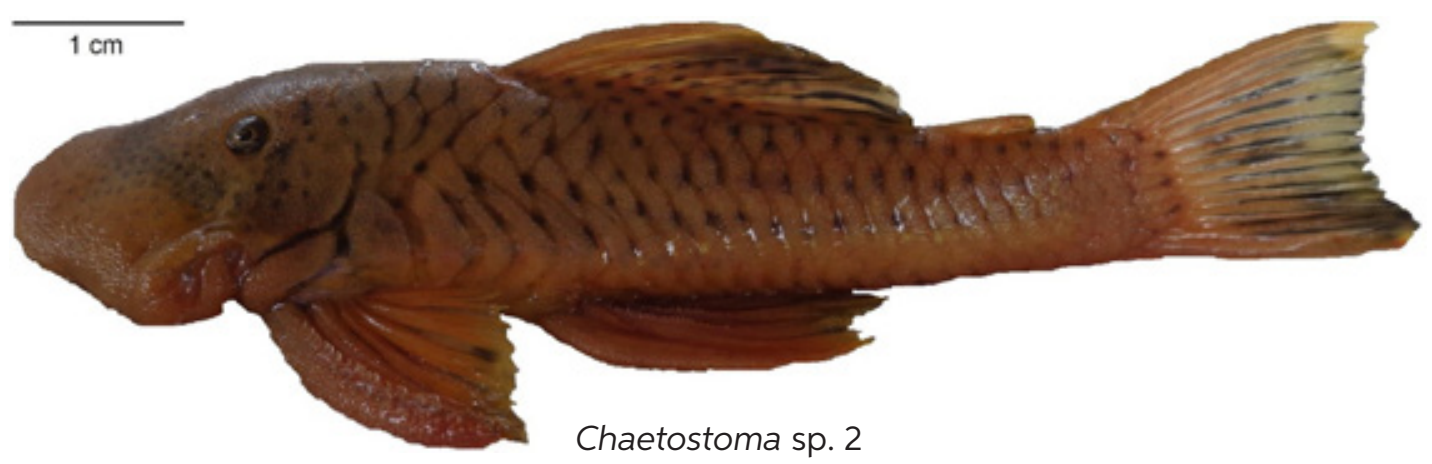




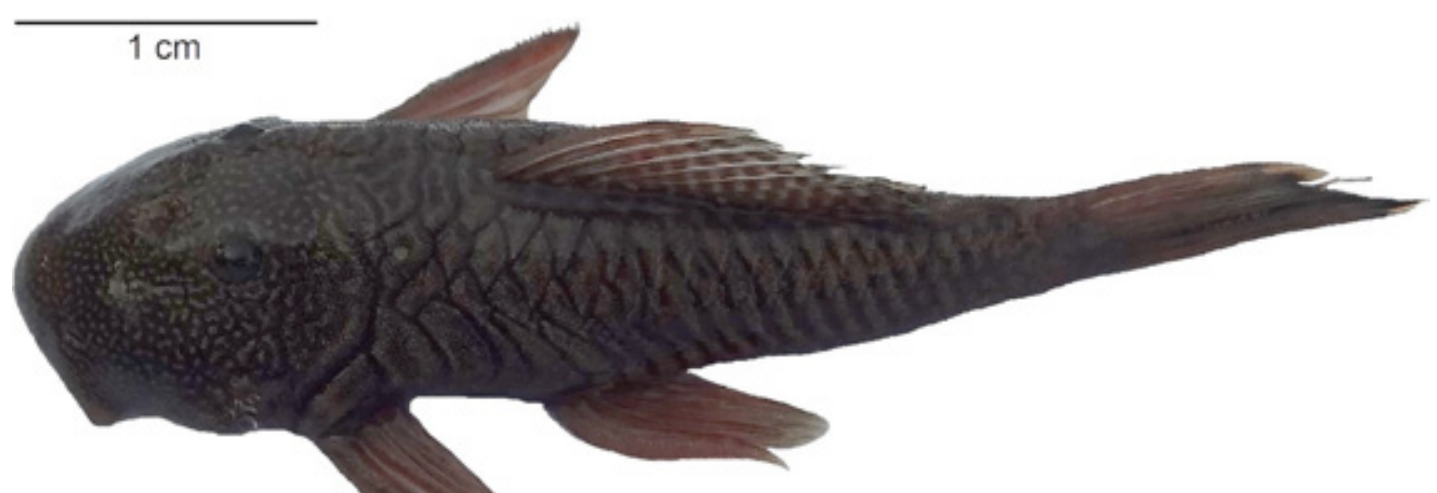

Chaetostoma sp. 3
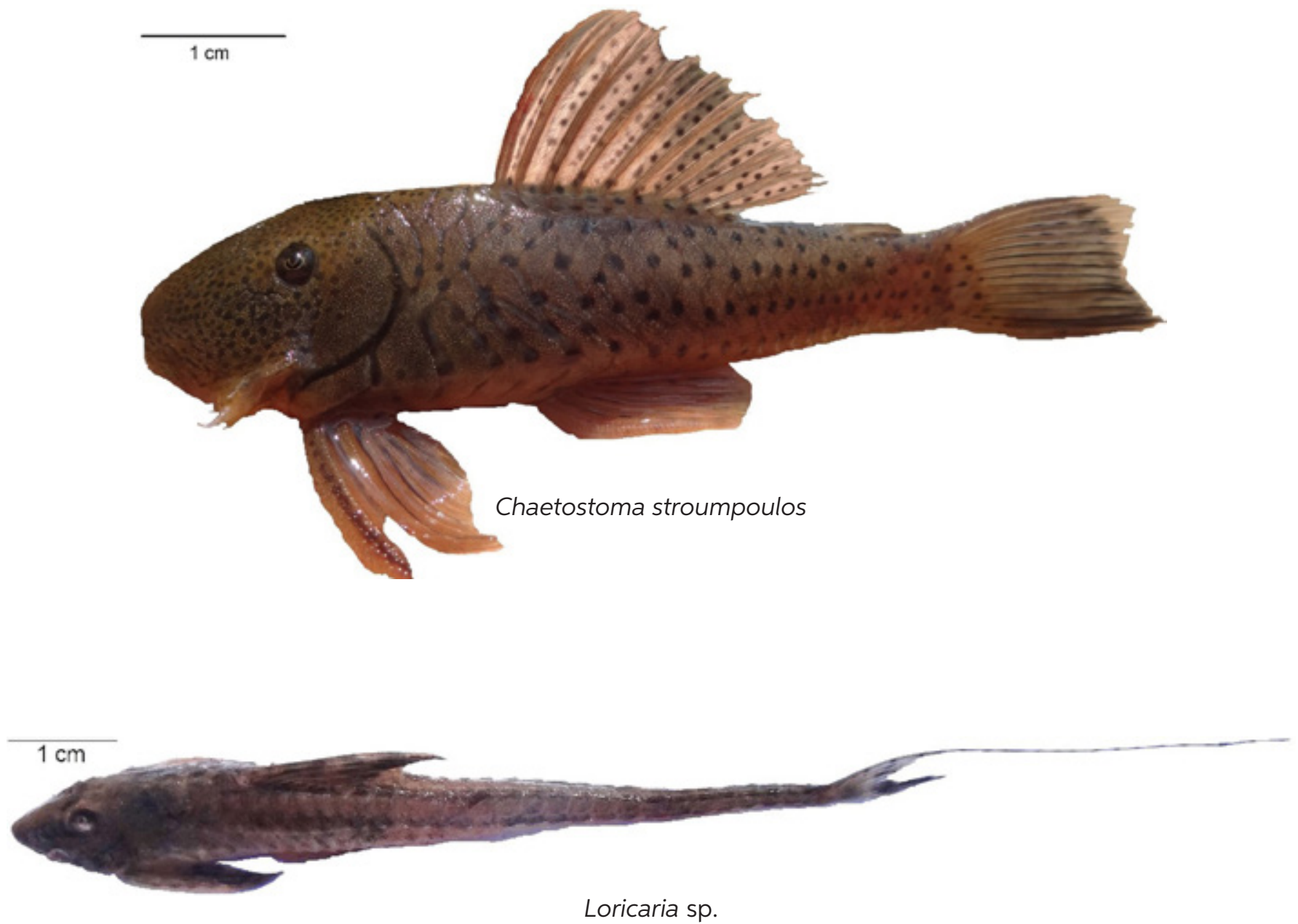

Esta obra está bajo una Licencia Creative Commons Atribución-NoComercial-SinDerivar 4.0 Internacional. 